\title{
The efficacy of transcranial magnetic stimulation (TMS) for negative symptoms in schizophrenia: A systematic review and meta-analysis
}

\author{
Rasmus Lorentzen ${ }^{1,2}$, Tuan D. Nguyen ${ }^{1,2}$, Alexander McGirr ${ }^{3,4,5}$, \\ Fredrik Hieronymus ${ }^{1,2,6}$, Søren D. Østergaard ${ }^{1,2}$ \\ ${ }^{1}$ Department of Affective Disorders, Aarhus University Hospital - Psychiatry, Aarhus, Denmark \\ ${ }^{2}$ Department of Clinical Medicine, Aarhus University, Aarhus, Denmark \\ ${ }^{3}$ Hotchkiss Brain Institute, University of Calgary, Calgary, Canada \\ ${ }^{4}$ Department of Psychiatry, Cumming School of Medicine, University of Calgary, Calgary, Canada \\ ${ }^{5}$ Mathison Centre for Mental Health Research and Education, University of Calgary, Calgary, Canada \\ ${ }^{6}$ Department of Pharmacology, Sahlgrenska Academy, University of Gothenburg, Gothenburg, Sweden
}

\section{Corresponding author}

Søren Dinesen Østergaard, MD PhD

Department of Affective Disorders

Aarhus University Hospital - Psychiatry

Palle Juul-Jensens Boulevard 175

Aarhus N

Denmark

Phone: +45 61282753

Email: soeoes@rm.dk 


\begin{abstract}
Several trials have shown preliminary evidence for the efficacy of Transcranial Magnetic

Stimulation (TMS) as a treatment for negative symptoms in schizophrenia. Here, we synthesize this literature in a systematic review and quantitative meta-analysis of double-blind randomized controlled trials of TMS in patients with schizophrenia. Specifically, MEDLINE, EMBASE, Web of Science, and PsycINFO were searched for sham-controlled, randomized trials of TMS among patients with schizophrenia. The standardized mean difference (SMD, Cohen's $d$ ) with $95 \%$ confidence intervals (CI) was calculated for each study (TMS vs. sham) and pooled across studies using an inverse variance random effects model. We identified 56 studies with a total of 2550 participants that were included in the meta-analysis. The pooled analysis showed statistically significant superiority of TMS (SMD=0.37, 95\%CI: 0.23; 0.52, p-value <0.00001), corresponding to a number needed to treat of 5. Furthermore, stratified analyses suggested that TMS targeting the left dorsolateral prefrontal cortex, using a stimulation frequency $>1 \mathrm{~Hz}$, and a stimulation intensity at or above the motor threshold, was most efficacious. There was, however, substantial heterogeneity and high risk of bias among the included studies. In conclusion, TMS appears to be an efficacious treatment option for patients with schizophrenia suffering from negative symptoms, but the optimal TMS parameters have yet to be resolved.
\end{abstract}




\section{Introduction}

Pharmacological treatment is the cornerstone of care in schizophrenia and other psychotic disorders [1]. Though positive symptoms (e.g., delusions and hallucinations) respond relatively well to pharmacological treatment, negative symptoms often do not respond to the same degree $[2,3]$. Indeed, patients with predominantly negative symptoms are more resistant to treatment than patients with primarily positive symptoms, and negative symptoms are strongly associated with low daily functioning and poor long-term prognosis [4-6]. Therefore, identification and development of efficacious treatments of negative symptoms is a priority $[3,7]$.

Transcranial magnetic stimulation (TMS) is a non-invasive treatment modality, which has been pursued in schizophrenia to treat both positive and negative symptoms, although with different methodologies and targets. Since the most recent reviews and meta-analyses studies on this topic [8-10], several new trials have emerged [11-19], with some using novel stimulation parameters as well as neuronavigation to better target key neurological structures, thereby possibly improving treatment outcomes. Here, we synthesize this literature in an up-to-date systematic review and quantitative meta-analysis of double-blind randomized controlled trials reporting on the efficacy of rTMS in the treatment of negative symptoms among patients with schizophrenia. 


\section{Methods}

\section{Protocol and Registration}

The study protocol was registered at the International Prospective Register of Systematic Reviews (PROSPERO, ID: CRD42021238828) [20] and carried out in accordance with the Preferred Reporting Items for Systematic Reviews and Meta-Analyses (PRISMA) guidelines [21].

\section{Information Sources and Screening}

MEDLINE (PubMed), PsycINFO, Web of Science and EMBASE were searched for relevant studies. Earlier reviews on the subject, clinicaltrials.gov, as well as citations of included studies were reviewed in order to find further eligible studies. The search was carried out on May $1^{\text {st }} 2021$ using the following search string in MEDLINE: ("schizophreni*” OR "schizoaffective disorder" OR "schizophreniform disorder" OR "schizophrenia"[MeSH Terms] OR "negative symptom*” OR “CHR” OR “Clinical High Risk” OR "Ultra High Risk” OR “UHR” OR "Psychotic Disorders"[MeSH Terms] OR "Psychotic Disorder*") AND ("transcranial magnetic stimulation" OR "TMS" OR "rTMS" OR "theta burst" OR "iTBS" OR “cTBS” OR Transcranial Magnetic Stimulation*"[MeSH Terms]). The analogue search strings used for the other databases are available in the Supplementary Material.

Titles and abstracts of studies identified via the search strategy described above were screened independently by two authors (RL and TDN) assisted by Covidence [22]. Full text versions of the studies deemed relevant after initial screening were subsequently assessed for eligibility.

\section{Eligibility Criteria}

The following inclusion criteria were employed:

- Randomized, sham-controlled trials of transcranial magnetic stimulation (e.g. rTMS or theta burst stimulation)

- Participants with a primary diagnosis of schizophrenia, schizoaffective disorder, schizophreniform disorder or another psychotic disorder according to the DSM-IV, DSM-5, or ICD-10.

- Adult participants $(\geq 18$ years) 
- Outcome measured using an established psychometric scale for negative symptoms in schizophrenia (e.g., the negative subscale of the Positive and Negative Syndromes Scale (PANSS-N) [23] or the Scale for Assessment of Negative Symptoms (SANS) [24].

The following exclusion criterion was employed:

- Co-initiation of other treatments, e.g. pharmacological treatment, as the results of such studies could be affected by an interaction effect between TMS and the co-initiated treatment.

\section{Data extraction}

The following items were extracted from each included study: Author name, publication year, country, study type (cross-over or parallel), analysis-type (per protocol or intention-to-treat (ITT)), number of participants, drop-out rates, mean age of participants, sex distribution of participants, diagnosis, whether samples were selected for predominantly negative symptoms, frequency and intensity of TMS including the total number of stimuli and number of treatments, TMS target, nature of the sham intervention, outcome measure (rating scale), post treatment scores, follow-up scores and post treatment depression scores, if available.

If these data were not reported, the authors were contacted by e-mail with a request to provide the data. If authors did not reply, data from graphs (if available) were extracted using the GetData Graph Digitizer [25]. Previous meta-analyses were screened for post-treatment outcome data required to compute effect sizes. Studies where data was not available upon request, via graphs or through previous meta-analyses, were excluded from the analyses.

\section{Evaluation of risk of bias}

Using the Cochrane Risk of Bias Tool 2.0 [26], the included studies were evaluated according to five domains of bias (articles in non-English languages were not evaluated): A) Randomization process, B) Deviations from intended interventions, C) Missing outcome data, D) Measurement of the outcome, and E) Selection of the reported result. The highest risk score assigned in one of these domains defined the overall risk of bias score for the study. Furthermore, potential publication bias was explored using a funnel plot. 


\section{Statistical Analysis}

The standardized mean difference between TMS and sham (SMD, Cohen's $d$ ) with 95\% confidence intervals (CI) was calculated for each study. SMDs were calculated based on endpoint scores or change scores for each group, with endpoint scores being preferred. If multiple outcome measures were used, PANSS-N was preferred. If a study did not provide standard deviations (SD) or data that could be used to calculate SD (e.g. standard error), the mean standard deviation across all studies of the same outcome measure was used. For cross-over studies, data was extracted after the first treatment phase (before cross-over) to exclude possible carry-over effects of treatment and thus regarded as a parallel design study.

SMDs were pooled using the inverse variance random effects model in Review Manager 5.3 [27]. This model takes into account both in-study and between-study variability. For the primary analysis, number needed to treat (NNT) was estimated using the method proposed by Kraemer and Kupfer [28]. Heterogeneity was assessed using the $I^{2}$-test with $I^{2}$-values $\geq 50 \%$ suggesting considerable heterogeneity. For subgroup analyses with heterogeneity $<50 \%$, the fixed effect model was used for analysis. For multi-arm studies, data from different active TMS treatment arms were pooled in the calculation of overall efficacy as to not duplicate data from the sham group, using the formulas provided in table 6.5a in the Cochrane Handbook [29].

Following the main analysis, separate effect size analyses were carried out i) after stratifying by type of TMS, ii) after stratifying by stimulation frequencies, iii) after stratifying by stimulation intensity, iv) for patients with predominantly negative symptoms, v) after excluding studies with data extracted from graphs, vi) after excluding studies with high risk of bias. vii) after stratifying by age, viii) after excluding studies reporting change-from-baseline scores, ix) focusing on long term effect using data from at least four weeks after the last treatment (the last follow up in each study was used), $\mathrm{x}$ ) focusing on the effect size of TMS for depressive symptoms (all depression measures allowed with a preference for the Calgary Depression Scale in Schizophrenia [30]), and finally xi) after excluding studies with data extracted from other reviews. 


\section{Results}

\section{Study Selection}

The search yielded 3287 articles of which 1573 were duplicates, resulting in 1714 studies that underwent title- and abstract screening (Figure 1). Following this screening, 1565 were excluded. This left 149 articles to be assessed in full text, of which 80 studies did not meet the eligibility criteria. Of the 69 eligible studies, 35 reported insufficient data and thus the authors were contacted by e-mail requesting additional data. The means and standard deviations of PANSS-N was the most common missing piece of information (i.e., from studies where only the total PANSS scores were reported). From these 35 studies, three author groups provided data [13, 18, 31], and data were extracted from graphs in an additional eight studies [19, 32-38]. Hence, 24 articles were excluded due to non-available data [39-62]. In total, the search yielded 45 includable studies, with 51 comparisons as a result of studies including multiple interventions [11-19, 31-38, 63-90]. No additional studies were found in citations or in the database of clinicaltrials.gov. Summary data was available from 14 studies reviewed by Wang and colleagues [10] from non-English reports, [87-89, 91-101], of which 3 was studies found through the database search, leaving a total of 56 studies and 62 comparisons [11-19, 31-38, 62-101].

\section{Study characteristics}

The 56 studies included 2550 participants, of whom 1440 received active treatment and 1110 sham treatment (Table 1). In the 54 studies $(n=2442)$ that reported the diagnoses of the participants, $98.8 \%$ had schizophrenia and $1.2 \%$ had schizoaffective disorder. The studies were conducted in 15 different countries, of which China was the most common $(n=24)$. Almost all included studies reported the outcome using PANSS-N or SANS with only one study using the Brief Psychiatric Rating Scale - Negative/Disorganized factor (BPRS-N/D) [65].

Several different active TMS modalities were used in the included trials, with some testing more than one active modality against sham treatment: rTMS (47 studies, 10 used $\leq 1 \mathrm{~Hz}, 38 \mathrm{used}>1 \mathrm{~Hz}$, 41 used unilateral treatment, and eight bilateral or midline treatment), TBS (9 studies, 5 used iTBS, 1 used cTBS, and 3 used unspecified TBS), and deep-TMS (2 studies) (see Supplementary Table 2, treatment characteristics). The mean total number of stimuli per trial was 25,684 varying from 
1200-80,000 stimuli. The majority of the studies $(n=39)$ had the left dorsolateral prefrontal cortex (L-DLPFC) as the primary stimulation target.

\section{Risk of Bias of Individual Studies}

Eight studies were regarded as having low risk of bias, 10 studies with "some concerns", and 23 studies with high risk of bias (Supplementary Table 3). The most common reason $(n=23)$ for "some concerns" was insufficient reporting whether the randomization sequence was concealed adequately (domain A). Improper analysis (e.g. "per protocol" analysis, domain B) and missing outcome data (domain C) were the most common reasons ( $n=12$ and $n=21$, respectively, with $n=11$ having both) for a study being regarded as having high risk of bias.

\section{Results of Individual Studies}

Standardized mean differences for the included studies are shown in Figure 2. Seventeen studies showed a statistically significant superior effect of TMS compared to sham treatment $[13,14,34$, $75,76,78,79,85-87,91,92,96-99,101]$ and one study found a statistically significant superior effect of sham treatment [32]. The remaining studies did not show a statistically significant difference between the treatment groups. There was considerable heterogeneity between the included studies $\left(I^{2}=65 \%\right)$.

\section{Synthesis of Results}

As evident from Figure 2, the overall SMD was 0.37 (95\%CI: $0.23 ; 0.52, p<0.00001)$ in favor of TMS, corresponding to an NNT of 5. The results of the secondary analyses are available in Table 2. Using follow-up data from at least four weeks after end of treatment yielded an SMD of 0.25 (95\%CI: 0.09; 0.40). Following exclusion of i) studies with data taken from graphs (SMD=0.40, 95\%CI: $0.24 ; 0.56)$, ii) studies with a high risk of bias (SMD=0.35, 95\%CI: $0.08 ; 0.62)$, or iii) studies using change-from-baseline scores (SMD=0.38, 95\%CI: 0.24; 0.53) did not impact the effect estimate substantially. Stimulation of L-DLPFC seemed to have a larger effect than other sites (SMD=0.51, 95\%CI: 0.33; 0.69 vs. $\mathrm{SMD}=0.05,95 \% \mathrm{CI}:-0.14 ; 0.23)$, however, there was considerable methodological heterogeneity in the "other" category. The SMD of TBS (SMD $=0.48$, 95\%CI: -0.01 ; 0.96) was similar to that of rTMS (SMD=0.46, 95\%CI: $0.27 ; 0.65$ ). The effect in participants with predominantly negative symptoms was highly significant (SMD $=0.45,95 \% \mathrm{CI}$ : 
medRxiv preprint doi: https://doi.org/10.1101/2021.11.05.21265787; this version posted November 8, 2021. The copyright holder for this preprint

(which was not certified by peer review) is the author/funder, who has granted medRxiv a license to display the preprint in perpetuity.

All rights reserved. No reuse allowed without permission.

$0.20 ; 0.70$ ), while no effect on depressive symptoms was observed (SMD=0.03, 95\%CI: -0.12 ;

0.18 .

\section{Risk of Bias Across Studies}

Based on the funnel plot (Figure 3), two outlying studies suggest some degree of asymmetry, indicating a small to moderate risk of publication bias. 


\section{Discussion}

Based on meta-analysis of 56 studies with a total of 2550 participants mainly with schizophrenia, we found a superior effect of active TMS on negative symptoms compared to sham treatment. The SMD was 0.37 (95\%CI: 0.23 ; 0.52) in favor of active TMS, translating to an NNT of 5. The superiority of active TMS remained statistically significant following a) exclusion of data extracted from graphs, b) exclusion of studies deemed to be at high risk of bias, and c) exclusion of studies reporting change-from-baseline scores. Further subgroup analyses suggested that using $>1 \mathrm{~Hz}$ stimulation $(\mathrm{SMD}=0.52$ vs. $\mathrm{SMD}=0.05)$, targeting the $\mathrm{L}-\mathrm{DLPFC}(\mathrm{SMD}=0.51 \mathrm{vs} . \mathrm{SMD}=0.05)$, and $\geq 100 \%$ motor threshold ( $\mathrm{SMD}=0.42$ vs. $\mathrm{SMD}=0.26$ ) may be more effective. However, there was considerable heterogeneity across the included studies and these results should be considered tentative. In contrast to a prior meta-analysis [8], we found no support for the suggestion that TMS should have particularly beneficial effect upon negative symptoms for younger individuals $(\mathrm{SMD}=0.33$ vs. $\mathrm{SMD}=0.40)$.

While there are prior meta-analysis on this topic, the present work covers substantially more participants (77\% more than Wang et al. [10]) and studies (80\% more studies than Osoegawa et al. [9]). Both of these prior meta-analyses also pointed to a beneficial effect of TMS on the negative symptoms of schizophrenia. This up-to-date meta-analysis therefore consolidates the sentiment that there may be a place for TMS in the treatment of negative symptoms in schizophrenia, which have a highly adverse effect on daily function and are often resistant to other types of treatment [5].

Several different brain areas were targeted by the studies included in this synthesis, in which subgroup analyses suggested that stimulation of the L-DLPFC had superior effect compared to other targets ( $\mathrm{SMD}=0.51$ vs. $\mathrm{SMD}=0.05)$. These results align with earlier studies that have found an inverse correlation between frontal lobe size and glucose metabolism, and negative symptom severity [102, 103]. Moreover, there are increasing data suggesting that the DLPFC has a privileged relationship with other structures implicated in negative symptoms, including the midline cerebellum (MC) [104]. The circuitry of the DLPFC in relation to negative symptoms will likely be an important area to study when developing stimulation targets in personalized medicine.

There are limitations to this study, which should be acknowledged by the readers. First, as there are phenomenological overlaps between negative and depressive symptoms and since depression 
responds well to TMS [105, 106], the relief of depressive symptoms during treatment could potentially confound the estimation of the effect on negative symptoms. However, our analysis of data from studies measuring depressive symptoms in the context of schizophrenia found no statistically significant efficacy regarding depressive symptoms, suggesting that the effect on negative symptoms is not confounded in this respect. Second, $56 \%$ of the evaluated studies were regarded as "high risk of bias" studies, which is a substantially larger proportion compared to the $13 \%$ reported in the review by Wang et al [10]. This difference is predominantly a consequence of classification as we used the Cochrane Risk of Bias Tool 2.0, while Wang et al. used the Cochrane Risk of Bias Tool 1.0. The most common reason for studies being considered as "high risk" in the context of the present review was missing data. We employed a relatively conservative $10 \%$ cut-off for missing data, but there is no agreed upon threshold [107] and the proportion of studies classified as "high risk of bias" can thus vary considerably between reviews. Third, we used a broad search strategy, but relevant studies may have been missed nevertheless. However, assuming that such potential misses occur at random, it should not have affected the reported efficacy estimates. Fourth, the inclusion of data drawn from reviews is suboptimal. However, the analysis excluding this data yielded results equivalent to those from the primary analysis. Fifth, while we conducted several subgroup analyses, formal (effect) moderator analysis was not conducted. Sixth, there was significant heterogeneity in outcome across the included studies, with $I^{2}$-assessments at $50 \%$ or above in all but six cases (65\% in the primary analysis; Figure 2). While this is likely partly due to the considerable heterogeneity of the TMS treatment provided across the included studies, other sources of heterogeneity, such as differences in sham conditions, patient populations, outcome measures, or random chance, are also likely contributors. Relatedly, in the review by He et al., a univariate meta-regression of stimulation frequency, total simulation, motor threshold, stimulation site, study design, and type of coil was conducted. None of these factors were shown to be the main source of heterogeneity.

In conclusion, this systematic review and quantitative synthesis of sham-controlled studies suggests that TMS is efficacious in the treatment of negative symptoms of schizophrenia. Although it appears that targeting the L-DLPFC, using a stimulation frequency $>1 \mathrm{~Hz}$, and stimulation intensity at or above the motor threshold are the most efficacious settings, the optimal treatment parameters are yet to be resolved. 
medRxiv preprint doi: https://doi.org/10.1101/2021.11.05.21265787; this version posted November 8, 2021. The copyright holder for this preprint

(which was not certified by peer review) is the author/funder, who has granted medRxiv a license to display the preprint in perpetuity.

All rights reserved. No reuse allowed without permission.

\section{Funding}

There was no specific funding for this study.

\section{Conflicts of interest}

AM has served as an advisor for Allergan Canada. SDØ received the 2020 Lundbeck Foundation Young Investigator Prize. Furthermore, SDØ owns units of mutual funds with stock tickers DKIGI, NBIDE, and WEKAFKI, as well as units of exchange traded funds with stock tickers TRET, 2B76, and LOCK. The remaining authors report no conflicts of interest. 


\section{References}

1. Guideline Statements and Implementation, in The American Psychiatric Association Practice Guideline for the Treatment of Patients With Schizophrenia.

2. Fusar-Poli, P., et al., Treatments of Negative Symptoms in Schizophrenia: Meta-Analysis of 168 Randomized Placebo-Controlled Trials. Schizophr Bull, 2015. 41(4): p. 892-9.

3. Buchanan, R.W., et al., The 2009 schizophrenia PORT psychopharmacological treatment recommendations and summary statements. Schizophr Bull, 2010. 36(1): p. 71-93.

4. $\quad$ Strauss, G.P., et al., Periods of recovery in deficit syndrome schizophrenia: a 20-year multifollow-up longitudinal study. Schizophr Bull, 2010. 36(4): p. 788-99.

5. Fenton, W.S. and T.H. McGlashan, Antecedents, symptom progression, and long-term outcome of the deficit syndrome in schizophrenia. Am J Psychiatry, 1994. 151(3): p. 351-6.

6. Leucht, S., et al., Sixty Years of Placebo-Controlled Antipsychotic Drug Trials in Acute Schizophrenia: Systematic Review, Bayesian Meta-Analysis, and Meta-Regression of Efficacy Predictors. Am J Psychiatry, 2017. 174(10): p. 927-942.

7. Kirkpatrick, B., et al., Assessing the efficacy of treatments for the deficit syndrome of schizophrenia. Neuropsychopharmacology, 2000. 22(3): p. 303-10.

8. Aleman, A., et al., Moderate effects of noninvasive brain stimulation of the frontal cortex for improving negative symptoms in schizophrenia: Meta-analysis of controlled trials. Neurosci Biobehav Rev, 2018. 89: p. 111-118.

9. Osoegawa, C., et al., Non-invasive brain stimulation for negative symptoms in schizophrenia: An updated systematic review and meta-analysis. Schizophr Res, 2018. 197: p. 34-44.

10. Wang, J., et al., Efficacy Towards Negative Symptoms and Safety of Repetitive Transcranial Magnetic Stimulation Treatment for Patients with Schizophrenia: A Systematic Review. Shanghai Arch Psychiatry, 2017. 29(2): p. 61-76.

11. Chauhan, P., et al., Efficacy of Intensive Cerebellar Intermittent Theta Burst Stimulation (iCiTBS) in Treatment-Resistant Schizophrenia: a Randomized Placebo-Controlled Study. Cerebellum, 2020.

12. Guan, H.Y., et al., High-frequency neuronavigated rTMS effect on clinical symptoms and cognitive dysfunction: a pilot double-blind, randomized controlled study in Veterans with schizophrenia. Transl Psychiatry, 2020. 10(1): p. 79.

13. Güleken, M.D., et al., The effect of bilateral high frequency repetitive transcranial magnetic stimulation on cognitive functions in schizophrenia. Schizophr Res Cogn, 2020. 22: p. 100183.

14. Kumar, N., et al., A randomized, double blind, sham-controlled trial of repetitive transcranial magnetic stimulation (rTMS) in the treatment of negative symptoms in schizophrenia. Brain Stimul, 2020. 13(3): p. 840-849.

15. Singh, S., et al., The safety and efficacy of adjunctive $20-\mathrm{Hz}$ repetitive transcranial magnetic stimulation for treatment of negative symptoms in patients with schizophrenia: A doubleblinded, randomized, sham-controlled study. Indian J Psychiatry, 2020. 62(1): p. 21-29.

16. Wang, L., et al., Intermittent theta burst stimulation (iTBS) adjustment effects of schizophrenia: Results from an exploratory outcome of a randomized double-blind controlled study. Schizophrenia Research, 2020. 216: p. 550-553. 
17. Xiu, M.H., et al., Cognitive Enhancing Effect of High-Frequency Neuronavigated rTMS in Chronic Schizophrenia Patients With Predominant Negative Symptoms: A Double-Blind Controlled 32-Week Follow-up Study. Schizophr Bull, 2020. 46(5): p. 1219-30.

18. Bation, R., et al., Intermittent theta burst stimulation for negative symptoms of schizophrenia-A double-blind, sham-controlled pilot study. NPJ Schizophr, 2021. 7(1): p. 10.

19. Pan, Z., et al., The Effects of Repetitive Transcranial Magnetic Stimulation in Patients with Chronic Schizophrenia: Insights from EEG Microstates. Psychiatry Res, 2021. 299: p. 113866.

20. https://www.crd.york.ac.uk/PROSPERO

21. Liberati, A., et al., The PRISMA statement for reporting systematic reviews and metaanalyses of studies that evaluate healthcare interventions: explanation and elaboration. Bmj, 2009. 339: p. b2700.

22. Covidence systematic review software, Veritas Health Innovation, Melbourne, Australia. Available at www.covidence.org

23. Kay, S.R., A. Fiszbein, and L.A. Opler, The positive and negative syndrome scale (PANSS) for schizophrenia. Schizophr Bull, 1987. 13(2): p. 261-76.

24. Andreasen, N.C., The Scale for the Assessment of Negative Symptoms (SANS): conceptual and theoretical foundations. Br J Psychiatry Suppl, 1989(7): p. 49-58.

25. http://getdata-graph-digitizer.com/

26. https://methods.cochrane.org/risk-bias-2

27. Review Manager (RevMan) [Computer program]. Version 5.4, The Cochrane Collaboration, 2020

28. Kraemer, H.C. and D.J. Kupfer, Size of treatment effects and their importance to clinical research and practice. Biol Psychiatry, 2006. 59(11): p. 990-6.

29. https://training.cochrane.org/handbook/current/chapter-06\#section-6-5-2-10

30. Addington, D., J. Addington, and E. Maticka-Tyndale, Assessing depression in schizophrenia: the Calgary Depression Scale. Br J Psychiatry Suppl, 1993(22): p. 39-44.

31. Novák, T., et al., The double-blind sham-controlled study of high-frequency rTMS $(20 \mathrm{~Hz})$ for negative symptoms in schizophrenia: negative results. Neuro Endocrinol Lett, 2006. 27(12): p. 209-13.

32. Chibbaro, G., et al., Repetitive transcranial magnetic stimulation in schizophrenic patients reporting auditory hallucinations. Neuroscience Letters, 2005. 383(1-2): p. 54-57.

33. Goyal, N., S.H. Nizamie, and P. Desarkar, Efficacy of adjuvant high frequency repetitive transcranial magnetic stimulation on negative and positive symptoms of schizophrenia: preliminary results of a double-blind sham-controlled study. J Neuropsychiatry Clin Neurosci, 2007. 19(4): p. 464-7.

34. Hajak, G., et al., High-frequency repetitive transcranial magnetic stimulation in schizophrenia: a combined treatment and neuroimaging study. Psychol Med, 2004. 34(7): p. 1157-63.

35. Mogg, A., et al., Repetitive transcranial magnetic stimulation for negative symptoms of schizophrenia: a randomized controlled pilot study. Schizophr Res, 2007. 93(1-3): p. 221-8.

36. Rosenberg, O., et al., Deep transcranial magnetic stimulation add-on for the treatment of auditory hallucinations: A double-blind study. Annals of General Psychiatry, 2012: p. 13. 
37. Schneider, A.L., T.L. Schneider, and H. Stark, Repetitive transcranial magnetic stimulation (rTMS) as an augmentation treatment for the negative symptoms of schizophrenia: a 4week randomized placebo controlled study. Brain Stimul, 2008. 1(2): p. 106-11.

38. Cordes, J., et al., Effects of $10 \mathrm{~Hz}$ repetitive transcranial magnetic stimulation (rTMS) on clinical global impression in chronic schizophrenia. Psychiatry Res, 2010. 177(1-2): p. 32-6.

39. Blumberger, D.M., et al., MRl-targeted repetitive transcranial magnetic stimulation of Heschl's gyrus for refractory auditory hallucinations. Brain Stimul, 2012. 5(4): p. 577-85.

40. Fitzgerald, P.B., et al., A double-blind sham-controlled trial of repetitive transcranial magnetic stimulation in the treatment of refractory auditory hallucinations. J Clin Psychopharmacol, 2005. 25(4): p. 358-62.

41. Koops, S., et al., Theta Burst Transcranial Magnetic Stimulation for Auditory Verbal Hallucinations: Negative Findings From a Double-Blind-Randomized Trial. Schizophr Bull, 2016. 42(1): p. 250-7.

42. Langguth, B., et al., Repetitive transkranielle Magnetstimulation bei Schizophrenie: Vorläufige Ergebnisse. Nervenheilkunde: Zeitschrift für interdisziplinaere Fortbildung, 2003. 22(7): p. 350-353.

43. Lee, S.H., et al., A double blind study showing that two weeks of daily repetitive TMS over the left or right temporoparietal cortex reduces symptoms in patients with schizophrenia who are having treatment-refractory auditory hallucinations. Neurosci Lett, 2005. 376(3): p. 177-81.

44. Lin, X.D., et al., Effects of Repetitive Transcranial Magnetic Stimulation Treatment on EventRelated Potentials in Schizophrenia. Chin Med J (Engl), 2018. 131(3): p. 301-306.

45. Maïza, O., et al., Impact of repetitive transcranial magnetic stimulation (rTMS) on brain functional marker of auditory hallucinations in schizophrenia patients. Brain Sciences, 2013. 3(2): p. 728-743.

46. Voineskos, A.N., et al., Effects of Repetitive Transcranial Magnetic Stimulation on Working Memory Performance and Brain Structure in People With Schizophrenia Spectrum Disorders: A Double-Blind, Randomized, Sham-Controlled Trial. Biol Psychiatry Cogn Neurosci Neuroimaging, 2020.

47. Wing, V.C., et al., High frequency repetitive transcranial magnetic stimulation reduces tobacco craving in schizophrenia. Schizophr Res, 2012. 139(1-3): p. 264-6.

48. Kim, E.-J., et al., Bilateral repetitive transcranial magnetic stimulation for auditory hallucinations in patients with schizophrenia: A randomized controlled, cross-over study. Clinical Psychopharmacology and Neuroscience, 2014. 12(3): p. 222-228.

49. Klirova, M., et al., Individualized rTMS neuronavigated according to regional brain metabolism $\left({ }^{18} F G D\right.$ PET) has better treatment effects on auditory hallucinations than standard positioning of rTMS: A double-blind, sham-controlled study. European Archives of Psychiatry and Clinical Neuroscience, 2013. 263(6): p. 475-484.

50. Mclntosh, A.M., et al., Transcranial magnetic stimulation for auditory hallucinations in schizophrenia. Psychiatry Res, 2004. 127(1-2): p. 9-17.

51. Vercammen, A., et al., Effects of bilateral repetitive transcranial magnetic stimulation on treatment resistant auditory-verbal hallucinations in schizophrenia: A randomized controlled trial. Schizophrenia Research, 2009. 114(1-3): p. 172-179.

52. Jandl, M., et al., Treating auditory hallucinations by transcranial magnetic stimulation: a randomized controlled cross-over trial. Neuropsychobiology, 2006. 53(2): p. 63-9. 
53. Kimura, H., et al., A randomized, sham-controlled study of high frequency rTMS for auditory hallucination in schizophrenia. Psychiatry Res, 2016. 241: p. 190-4.

54. Mendes-Filho, V.A., et al., Effects of repetitive transcranial magnetic stimulation over supplementary motor area in patients with schizophrenia with obsessive-compulsivesymptoms: A pilot study. Psychiatry Res, 2016. 242: p. 34-38.

55. Rollnik, J.D., et al., High frequency repetitive transcranial magnetic stimulation (rTMS) of the dorsolateral prefrontal cortex in schizophrenic patients. Neuroreport, 2000. 11(18): p. 4013-5.

56. Hoffman, R.E., et al., Transcranial magnetic stimulation of left temporoparietal cortex in three patients reporting hallucinated "voices". Biol Psychiatry, 1999. 46(1): p. 130-2.

57. Hoffman, R.E., et al., Transcranial magnetic stimulation and auditory hallucinations in schizophrenia. Lancet, 2000. 355(9209): p. 1073-5.

58. Hoffman, R.E., et al., Transcranial magnetic stimulation of left temporoparietal cortex and medication-resistant auditory hallucinations. Arch Gen Psychiatry, 2003. 60(1): p. 49-56.

59. Hoffman, R.E., et al., Temporoparietal Transcranial Magnetic Stimulation for Auditory Hallucinations: Safety, Efficacy and Moderators in a Fifty Patient Sample. Biological Psychiatry, 2005. 58(2): p. 97-104.

60. Hoffman, R.E., et al., Transcranial magnetic stimulation of Wernicke's and Right homologous sites to curtail "voices": a randomized trial. Biol Psychiatry, 2013. 73(10): p. 1008-14.

61. Jin, Y., et al., Alpha EEG guided TMS in schizophrenia. Brain Stimul, 2012. 5(4): p. 560-8.

62. Jin, Y., et al., Therapeutic effects of individualized alpha frequency transcranial magnetic stimulation ( $\alpha T M S$ ) on the negative symptoms of schizophrenia. Schizophrenia Bulletin, 2006. 32(3): p. 556-561.

63. Bais, L., et al., Short and long term effects of left and bilateral repetitive transcranial magnetic stimulation in schizophrenia patients with auditory verbal hallucinations: $a$ randomized controlled trial. PLoS One, 2014. 9(10): p. e108828.

64. Barr, M.S., et al., A randomized controlled trial of sequentially bilateral prefrontal cortex repetitive transcranial magnetic stimulation in the treatment of negative symptoms in schizophrenia. Brain Stimul, 2012. 5(3): p. 337-346.

65. de Jesus, D.R., et al., A pilot double-blind sham-controlled trial of repetitive transcranial magnetic stimulation for patients with refractory schizophrenia treated with clozapine. Psychiatry Research, 2011. 188(2): p. 203-207.

66. Dlabac-de Lange, J.J., et al., Efficacy of bilateral repetitive transcranial magnetic stimulation for negative symptoms of schizophrenia: results of a multicenter double-blind randomized controlled trial. Psychol Med, 2015. 45(6): p. 1263-75.

67. Dollfus, S., et al., High-Frequency Neuronavigated rTMS in Auditory Verbal Hallucinations: A Pilot Double-Blind Controlled Study in Patients With Schizophrenia. Schizophrenia Bulletin, 2018. 44(3): p. 505-514.

68. Fitzgerald, P.B., et al., A study of the effectiveness of bilateral transcranial magnetic stimulation in the treatment of the negative symptoms of schizophrenia. Brain Stimul, 2008. 1(1): p. 27-32.

69. Garg, S., et al., The efficacy of cerebellar vermal deep high frequency (theta range) repetitive transcranial magnetic stimulation (rTMS) in schizophrenia: A randomized rater blind-sham controlled study. Psychiatry Res, 2016. 243: p. 413-20. 
70. Holi, M.M., et al., Left prefrontal repetitive transcranial magnetic stimulation in schizophrenia. Schizophr Bull, 2004. 30(2): p. 429-34.

71. Huang, W., et al., Effect of Repetitive Transcranial Magnetic Stimulation on Cigarette Smoking in Patients with Schizophrenia. Shanghai Arch Psychiatry, 2016. 28(6): p. 309-317.

72. Klein, E., et al., Right prefrontal slow repetitive transcranial magnetic stimulation in schizophrenia: a double-blind sham-controlled pilot study. Biol Psychiatry, 1999. 46(10): p. 1451-4.

73. $\mathrm{Li}, \mathrm{H}$., et al., Effects of transcranial direct current stimulation (tDCS) for auditory hallucinations: A systematic review. Shanghai Archives of Psychiatry, 2016. 28(6): p. 301308.

74. Paillère-Martinot, M.L., et al., Active and placebo transcranial magnetic stimulation effects on external and internal auditory hallucinations of schizophrenia. Acta Psychiatr Scand, 2017. 135(3): p. 228-238.

75. Prikryl, R., et al., Treatment of negative symptoms of schizophrenia using repetitive transcranial magnetic stimulation in a double-blind, randomized controlled study. Schizophr Res, 2007. 95(1-3): p. 151-7.

76. Prikryl, R., et al., Does repetitive transcranial magnetic stimulation have a positive effect on working memory and neuronal activation in treatment of negative symptoms of schizophrenia? Neuroendocrinology Letters, 2012. 33(1): p. 90-97.

77. Prikryl, R., et al., Repetitive transcranial magnetic stimulation reduces cigarette consumption in schizophrenia patients. Prog Neuropsychopharmacol Biol Psychiatry, 2014. 49: p. 30-5.

78. Prikryl, R., et al., A detailed analysis of the effect of repetitive transcranial magnetic stimulation on negative symptoms of schizophrenia: A double-blind trial. Schizophrenia Research, 2013. 149(1-3): p. 167-173.

79. Quan, W.X., et al., The effects of high-frequency repetitive transcranial magnetic stimulation (rTMS) on negative symptoms of schizophrenia and the follow-up study. Neurosci Lett, 2015. 584: p. 197-201.

80. Rabany, L., L. Deutsch, and Y. Levkovitz, Double-blind, randomized sham controlled study of deep-TMS add-on treatment for negative symptoms and cognitive deficits in schizophrenia. J Psychopharmacol, 2014. 28(7): p. 686-90.

81. Rosa, M.O., et al., Effects of repetitive transcranial magnetic stimulation on auditory hallucinations refractory to clozapine. J Clin Psychiatry, 2007. 68(10): p. 1528-32.

82. Saba, G., F. Schurhoff, and M. Leboyer, Therapeutic and neurophysiologic aspects of transcranial magnetic stimulation in schizophrenia. Neurophysiologie Clinique, 2006. 36(3): p. 185-194.

83. Tikka, S.K., et al., Safety and efficacy of adjunctive $T$ burst repetitive transcranial magnetic stimulation to right inferior parietal lobule in schizophrenia patients with first-rank symptoms a pilot, exploratory study. Journal of ECT, 2017. 33(1): p. 43-51.

84. Wobrock, T., et al., Left prefrontal high-frequency repetitive transcranial magnetic stimulation for the treatment of schizophrenia with predominant negative symptoms: a sham-controlled, randomized multicenter trial. Biol Psychiatry, 2015. 77(11): p. 979-88.

85. Zhao, S., et al., Randomized controlled trial of four protocols of repetitive transcranial magnetic stimulation for treating the negative symptoms of schizophrenia. Shanghai Arch Psychiatry, 2014. 26(1): p. 15-21. 
86. Zhuo, K., et al., Repetitive transcranial magnetic stimulation as an adjunctive treatment for negative symptoms and cognitive impairment in patients with schizophrenia: a randomized, double-blind, sham-controlled trial. Neuropsychiatr Dis Treat, 2019. 15: p. 1141-1150.

87. Gan, J., et al., [Effectiveness and safety of high dose transcranial magnetic stimulation in schizophrenia with refractory negative symptoms: a randomized controlled study]. Zhonghua Yi Xue Za Zhi, 2015. 95(47): p. 3808-12.

88. Ren, Y.-P., et al., Effects of high frequency repetitive transcranial magnetic stimulation on refractory negative symptom of schizophrenia: A double blind, randomized controlled trial. Chinese Mental Health Journal, 2011. 25(2): p. 89-92.

89. $\mathrm{Xu}, \mathrm{W} . J$. , et al., Double-blind control trial of alpha electroencephalogram-guided transcranial magnetic stimulation treatment for schizophrenia. Chinese Journal of Clinical Rehabilitation, 2006. 10(46): p. 22-24.

90. Wen-Xiang, Q., et al., Effects of low frequency repetitive transcranial magnetic stimulation on auditory hallucination in patients with schizophrenia. Chinese Mental Health Journal, 2012. 26(3): p. 204-208.

91. Chen, H.Y., et al., Effect of adjunctive treatment with repetitive transcranial magnetic stimulation on exploratory eye movements and negative symptoms in schizophrenic patients: a randomized, double-blind, sham-controlled study. Shanghai Archives of Psychiatry, 2011. 23: p. 200-206.

92. Duan HF, G.J., Zhu XQ, Cao LJ, Shi ZJ, Gao CY, et al., Therapeutic effect of repetitive transcranial magnetic

stimulation for refractor y negative symptom of

schizophrenia. Xinxiang Yi Xue Yuan Xue Bao, 2013. 30.

93. Gan JL, C.Z., Duan HF, Zhu XQ, Shi ZJ, Gao CY, et al., A randomized controlled trial of a short pulsed transcranial magnetic stimulation in the treatment of refractory negative symptoms of schizophrenia. Zhong Hua Jing

Shen Ke Za Zhi, 2014(03): p. 191-192.

94. Gan JL, D.H., Cheng ZX, Shi ZJ, Gao CY, Liang XJ, et al, Effects of repetitive transcranial magnetic stimulation on schizophrenia with refractory negative symptoms and brainderived neurotrophic factor. Zhongguo Shen Jing Jing

Shen Ji Bing Za Zhi, 2014. 2014.

95. LiuH, L.H., Liu R, Wang JJ., The analysis of curative effect of negative symptoms in schizophrenic patients after the treatment of repetitive transcranial magnetic stimu-lation (rTMS). Xian Dai Dian Sheng Li XueZaZhi, 2008.

96. Ma SJ, W.Z., Huang YQ, Lin LB, Gao ZS. , Clinical efficacy of repetitive transcranial magnetic stimulation on first episode schizophrenia patients. ZhongHua Lin Chuang

Yi Shi Za Zhi (Dian Zi Ban), 2016.

97. Xu Q, Z.Y., Cheng ZH. , Efficacy and safety of repetitive transcranial magnetic stimulation in the treatment of negative symptoms of chronic schizophrenia. Zhong Hua Yi Xue Hui Di Shi Qi Ci Quan Guo Xin Wei Yi Xue Xue Shu Hui Yi Lun Wen Ji, 2015.

98. Zhang JJ, Z.X., Li H, Zhong XL, Cheng ZW, Liao LW, et and al., Double-blind randomized controlled trial of repetitive transcranial magnetic stimulation in the treatment of the negative symptoms of schizophrenia]. Shanghai Arch

Psychiatry., 2010. 
medRxiv preprint doi: https://doi.org/10.1101/2021.11.05.21265787; this version posted November 8, 2021. The copyright holder for this preprint (which was not certified by peer review) is the author/funder, who has granted medRxiv a license to display the preprint in perpetuity.

All rights reserved. No reuse allowed without permission.

99. Zhang $\mathrm{CH}, \mathrm{Y} . \mathrm{Z}$., Zhang G, Yang GH., Study on effect of repetitive transcranial magnetic stimulation combined with ziprasidone in the treatment of the negative symptoms of schizophrenia. Zhongguo Xian Dai Yi Yao Za Zhi., 2015.

100. Zheng LN, G.Q., Li H, Li CB, Wang JJ. , Effects of repetitive transcranial magnetic stimulation with different paradigms on the cognitive function and psychotic symptoms of schizophrenia patients. Beijing Da Xue Xue Bao (Yi

Xue Ban), 2012.

101. Bai Li, G.J., Liang Xuejun, Duan Huifeng, Gao Cunyou, Effects of repetitive transcranial magnetic stimulation on diffusion tensor imaging and negative symptoms in patients with schizophrenia. Chinese Journal of Health Psychology, 2015. 23(5): p. 649-653.

102. Tamminga, C.A., et al., Limbic System Abnormalities Identified in Schizophrenia Using Positron Emission Tomography With Fluorodeoxyglucose and Neocortical Alterations With Deficit Syndrome. Archives of General Psychiatry, 1992. 49(7): p. 522-530.

103. Wible, C.G., et al., Prefrontal cortex, negative symptoms, and schizophrenia: an MRI study. Psychiatry Research: Neuroimaging, 2001. 108(2): p. 65-78.

104. Brady, R.O., Jr., et al., Cerebellar-Prefrontal Network Connectivity and Negative Symptoms in Schizophrenia. Am J Psychiatry, 2019. 176(7): p. 512-520.

105. Brunoni, A.R., et al., Repetitive Transcranial Magnetic Stimulation for the Acute Treatment of Major Depressive Episodes: A Systematic Review With Network Meta-analysis. JAMA Psychiatry, 2017. 74(2): p. 143-152.

106. Nguyen, T.D., et al., The efficacy of repetitive transcranial magnetic stimulation (rTMS) for bipolar depression: A systematic review and meta-analysis. J Affect Disord, 2021. 279: p. 250-255.

107. https://training.cochrane.org/handbook/current/chapter-08\#section-8-5 
medRxiv preprint doi: https://doi.org/10.1101/2021.11.05.21265787; this version posted November 8, 2021. The copyright holder for this preprint (which was not certified by peer review) is the author/funder, who has granted medRxiv a license to display the preprint in perpetuity.

All rights reserved. No reuse allowed without permission.

Figure 1: PRISMA flowchart

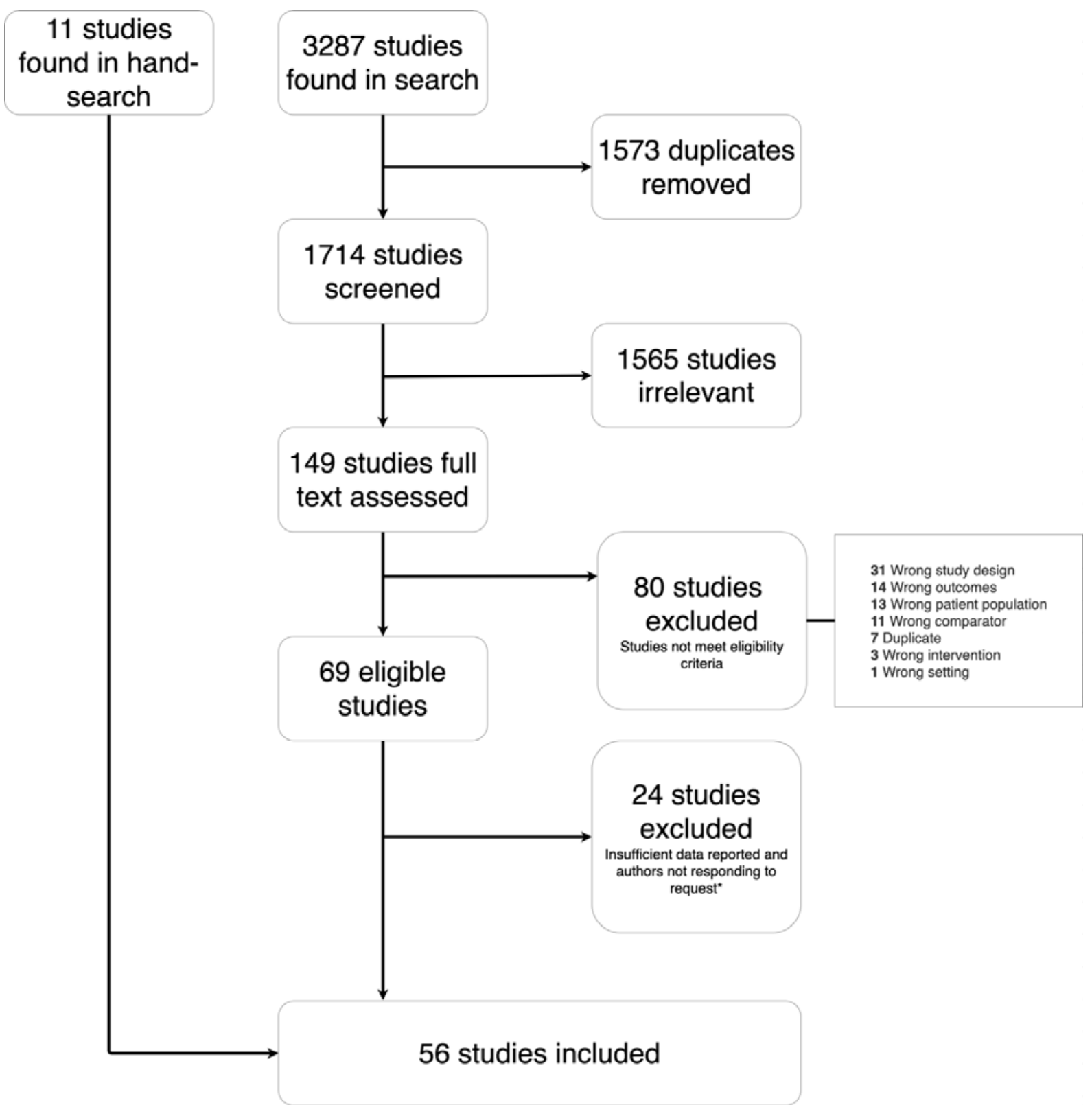

*Authors were contacted by e-mail. If data was not provided and data could not be taken from graphs, the study was excluded. 
Table 1: Characteristics of included studies

\begin{tabular}{|c|c|c|c|c|c|c|c|c|c|c|c|c|c|c|c|c|c|c|}
\hline Author & Year & Country & $\mathrm{Na}_{\mathrm{a}}$ & $\mathrm{N}_{\mathrm{c}}$ & $\begin{array}{l}\text { Mean } \\
\text { age }\end{array}$ & $\begin{array}{l}\mathrm{P} \\
\mathrm{N} \\
\mathrm{S}\end{array}$ & Analysis & $\begin{array}{l}\text { Study } \\
\text { type }\end{array}$ & $\begin{array}{c}\% \\
\text { males }\end{array}$ & $\begin{array}{c}\text { Drop-out } \\
\text { rate }\end{array}$ & $\begin{array}{l}\text { Outcome } \\
\text { score }\end{array}$ & $\begin{array}{l}\text { TMS } \\
\text { type }\end{array}$ & Sham type & $\mathrm{Hz}$ & $\%$ MT & $\begin{array}{l}\text { Treatment } \\
\text { Sessions }\end{array}$ & $\begin{array}{c}\text { total } \\
\text { number of } \\
\text { stimuli }\end{array}$ & Brain tar \\
\hline Bai & 2015 & China & 36 & 35 & 34,9 & $\mathrm{NI}$ & $\mathrm{NI}$ & $\mathrm{NI}$ & $\mathrm{NI}$ & $\mathrm{NI}$ & PANSS-N & rTMS & $\mathrm{NI}$ & 10 & $100 \%$ & $\mathrm{NI}$ & 25000 & L-DLPFC \\
\hline Bais & 2014 & Netherlands & 31 & 16 & 36.2 & $\mathrm{~N}$ & ITT & Par & $59 \%$ & $9 \%$ & PANSS-N & rTMS & Sham coil & 1 & $90 \%$ & 12 & 14400 & $\begin{array}{l}\text { B-DLPFC, } \\
\text { L-DLPFC }\end{array}$ \\
\hline Barr & 2012 & Canada & 13 & 12 & 45.4 & $\mathrm{~N}$ & PP & Par & $68 \%$ & $24 \%$ & $\begin{array}{l}\text { PANSS-N, } \\
\text { SANS }\end{array}$ & rTMS & $90^{\circ}$ & 20 & $90 \%$ & 20 & 30000 & B-DLPFC \\
\hline Bation & 2021 & France & 12 & 10 & 35.5 & $\mathrm{Y}$ & ITT & Par & $95 \%$ & $0 \%$ & $\begin{array}{l}\text { SANS, } \\
\text { PANSS-N }\end{array}$ & iTBS & Sham coil & 50 & $80 \%$ & 20 & 19800 & L-DLPFC \\
\hline Chauhan & 2020 & India & 19 & 17 & 40.2 & $\mathrm{~N}$ & ITT & Par & $42 \%$ & $17 \%$ & PANSS-N & iTBS & Sham coil & 50 & $80 \%$ & 10 & 12000 & MC \\
\hline Chen & 2011 & China & 24 & 22 & 38.5 & $\mathrm{NI}$ & $\mathrm{NI}$ & $\mathrm{NI}$ & $\mathrm{NI}$ & $\mathrm{NI}$ & PANSS-N & iTBS & $\mathrm{NI}$ & $\mathrm{NI}$ & $80 \%$ & 20 & 48000 & L-DLPFC \\
\hline Chibbaro & 2005 & Italy & 8 & 8 & 40.4 & $\mathrm{~N}$ & $\mathrm{NI}$ & Par & $69 \%$ & $\mathrm{NI}$ & SANS & rTMS & $45^{\circ}$ & 1 & $90 \%$ & 4 & 3600 & L-TPC \\
\hline Cordes & 2010 & Germany & 12 & 13 & 34.4 & Y & PP & Par & $100 \%$ & $4 \%$ & PANSS-N & rTMS & Sham coil & 10 & $110 \%$ & 10 & 10000 & L-DLPFC \\
\hline de Jesus & 2011 & Brazil & 8 & 9 & 39.5 & $\mathrm{~N}$ & ITT & Par & $71 \%$ & $0 \%$ & BPRS-N/D & rTMS & $45^{\circ}$ & 1 & $90 \%$ & 20 & 23040 & L-TPC \\
\hline $\begin{array}{l}\text { Dlabac-de } \\
\text { Lange }\end{array}$ & 2014 & Netherlands & 16 & 16 & 35.5 & Y & ITT & Par & $81 \%$ & $0 \%$ & $\begin{array}{l}\text { PANSS-N, } \\
\text { SANS }\end{array}$ & rTMS & $90^{\circ}$ & 10 & $90 \%$ & 30 & 60000 & B-DLPFC \\
\hline Dollfus & 2018 & France & 26 & 33 & 38.3 & $\mathrm{~N}$ & PP & Par & $54 \%$ & $20 \%$ & PANSS-N & rTMS & Sham coil & 20 & $80 \%$ & 4 & 10400 & L-STS \\
\hline Duan & 2013 & China & 21 & 20 & 26.9 & $\mathrm{NI}$ & $\mathrm{NI}$ & $\mathrm{NI}$ & $\mathrm{NI}$ & $\mathrm{NI}$ & PANSS-N & rTMS & $\mathrm{NI}$ & 10 & $100 \%$ & 20 & $\mathrm{NI}$ & L-DLPFC \\
\hline Fitzgerald & 2008 & Australia & 12 & 8 & 34.7 & $\mathrm{Y}$ & ITT & Par & $80 \%$ & $25 \%$ & $\begin{array}{l}\text { PANSS-N, } \\
\text { SANS }\end{array}$ & rTMS & $90^{\circ}$ & 10 & $110 \%$ & 15 & 30000 & B-PFC \\
\hline Gan (a) & 2014 & China & 20 & 21 & 26.9 & $\mathrm{NI}$ & $\mathrm{NI}$ & $\mathrm{NI}$ & $\mathrm{NI}$ & $\mathrm{NI}$ & PANSS-N & TBS & $\mathrm{NI}$ & $\mathrm{NI}$ & $100 \%$ & 20 & $\mathrm{NI}$ & L-DLPFC \\
\hline Gan (b) & 2014 & China & 38 & 37 & 27.1 & $\mathrm{NI}$ & $\mathrm{NI}$ & $\mathrm{NI}$ & $\mathrm{NI}$ & $\mathrm{NI}$ & PANSS-N & rTMS & $\mathrm{NI}$ & 10 & $100 \%$ & 20 & $\mathrm{NI}$ & L-DLPFC \\
\hline Gan & 2015 & China & 32 & 35 & 28.5 & $\mathrm{NI}$ & $\mathrm{NI}$ & $\mathrm{NI}$ & $\mathrm{NI}$ & $\mathrm{NI}$ & PANSS-N & rTMS & $\mathrm{NI}$ & 10 & $100 \%$ & 20 & 80000 & L-DLPFC \\
\hline Garg & 2016 & India & 20 & 20 & 31.3 & $\mathrm{~N}$ & PP & Par & $83 \%$ & $15 \%$ & PANSS-N & rTMS & $45^{\circ}$ & $5-7$ & $100 \%$ & 10 & 6000 & MC \\
\hline Goyal & 2007 & India & 5 & 5 & 27.4 & $\mathrm{~N}$ & ITT & Par & $100 \%$ & $0 \%$ & PANSS-N & rTMS & $45^{\circ}$ & 10 & $110 \%$ & 10 & 9800 & L-PFC \\
\hline Guan & 2020 & China & 28 & 28 & 54.6 & Y & ITT & Par & $100 \%$ & $27 \%$ & PANSS-N & rTMS & Sham coil & 20 & $110 \%$ & 40 & 64000 & L-DLPFC \\
\hline Güleken & 2020 & Turkey & 11 & 10 & 35.1 & $\mathrm{~N}$ & PP & Par & $67 \%$ & $13 \%$ & $\begin{array}{l}\text { PANSS-N, } \\
\text { SANS }\end{array}$ & rTMS & $90^{\circ}$ & 20 & $90 \%$ & 20 & 40000 & B-DLPF \\
\hline Hajak & 2004 & Germany & 10 & 10 & 40.4 & $\mathrm{~N}$ & ITT & Par & $40 \%$ & $0 \%$ & PANSS-N & rTMS & Sham coil & 10 & $110 \%$ & 10 & 10000 & L-DLPFC \\
\hline Holi & 2004 & Finland & 11 & 11 & 36.0 & $\mathrm{~N}$ & ITT & Par & $86 \%$ & $9 \%$ & PANSS-N & rTMS & $90^{\circ}$ & 10 & $100 \%$ & 10 & 10000 & L-DLPFC \\
\hline Huang & 2016 & China & 19 & 18 & 39.8 & $\mathrm{~N}$ & PP & Par & $100 \%$ & $5 \%$ & PANSS-N & rTMS & Sham coil & 10 & $110 \%$ & 21 & 42000 & L-DLPFC \\
\hline Klein & 1999 & Israel & 16 & 15 & 29.7 & $\mathrm{~N}$ & PP & Par & $37 \%$ & $11 \%$ & PANSS-N & rTMS & $90^{\circ}$ & 1 & $110 \%$ & 10 & 1200 & R-PFC \\
\hline Kumar & 2020 & India & 50 & 50 & 36.3 & Y & ITT & Par & $57 \%$ & $7 \%$ & $\begin{array}{l}\text { PANSS-N, } \\
\text { SANS }\end{array}$ & rTMS & Sham coil & 20 & $100 \%$ & 20 & 40000 & L-DLPFC \\
\hline $\mathrm{Li}$ & 2016 & $\begin{array}{l}\text { Taiwan/ } \\
\text { China }\end{array}$ & 25 & 22 & 45.0 & Y & ITT & Par & $49 \%$ & $19 \%$ & $\begin{array}{l}\text { SANS, } \\
\text { PANSS }\end{array}$ & rTMS & Sham coil & 10 & $110 \%$ & 20 & 30000 & L-DLPFC \\
\hline Liu & 2008 & China & 13 & 12 & 34.4 & $\mathrm{NI}$ & $\mathrm{NI}$ & $\mathrm{NI}$ & $\mathrm{NI}$ & $\mathrm{NI}$ & PANSS-N & rTMS & $\mathrm{NI}$ & 10 & $110 \%$ & 20 & 30000 & L-DLPFC \\
\hline Ma & 2016 & China & 58 & 60 & $\mathrm{NI}$ & $\mathrm{NI}$ & $\mathrm{NI}$ & $\mathrm{NI}$ & $\mathrm{NI}$ & $\mathrm{NI}$ & PANSS-N & rTMS & $\mathrm{NI}$ & 10 & $90 \%$ & 20 & 20000 & L-DLPFC \\
\hline Mogg & 2007 & UK & 8 & 9 & 39.1 & $Y$ & ITT & Par & $94 \%$ & $0 \%$ & PANSS-N & rTMS & Sham coil & 10 & $110 \%$ & 10 & 20000 & L-DLPFC \\
\hline
\end{tabular}




\begin{tabular}{|c|c|c|c|c|c|c|c|c|c|c|c|c|c|c|c|c|c|c|}
\hline Novak & 2006 & $\begin{array}{l}\text { Czech } \\
\text { Republic }\end{array}$ & 8 & 8 & 33.6 & $\mathrm{Y}$ & PP & Par & $75 \%$ & $11 \%$ & PANSS-N & rTMS & $90^{\circ}$ & 20 & $90 \%$ & 10 & 20000 & L-DLPFC \\
\hline $\begin{array}{l}\text { Paillère- } \\
\text { Martinot }\end{array}$ & 2016 & France & 15 & 12 & 31.5 & $\mathrm{~N}$ & ITT & Par & $56 \%$ & $4 \%$ & SANS & rTMS & Sham coil & 1 & $100 \%$ & 10 & 12000 & $\begin{array}{l}\text { L-STG, L- } \\
\text { MTG }\end{array}$ \\
\hline Pan & 2021 & China & 16 & 19 & 57.0 & $\mathrm{~N}$ & ITT & Par & $68 \%$ & $8 \%$ & PANSS-N & rTMS & Sham coil & 10 & $110 \%$ & 20 & 24000 & L-DLPFC \\
\hline Prikryl & 2007 & $\begin{array}{l}\text { Czech } \\
\text { Republic }\end{array}$ & 11 & 11 & 34.1 & $Y$ & $\mathrm{NI}$ & Par & $100 \%$ & $\mathrm{NI}$ & $\begin{array}{l}\text { PANSS-N, } \\
\text { SANS }\end{array}$ & rTMS & $90^{\circ}$ & 10 & $110 \%$ & 15 & 22500 & L-DLPFC \\
\hline Prikryl & 2012 & $\begin{array}{l}\text { Czech } \\
\text { Republic }\end{array}$ & 19 & 11 & 33.0 & $\mathrm{Y}$ & $\mathrm{NI}$ & Par & $100 \%$ & $\mathrm{NI}$ & PANSS-N & rTMS & Sham coil & 10 & $110 \%$ & 15 & 22500 & L-DLPFC \\
\hline Prikryl & 2013 & $\begin{array}{l}\text { Czech } \\
\text { Republic }\end{array}$ & 23 & 17 & 33.1 & $\mathrm{Y}$ & PP & Par & $100 \%$ & $11 \%$ & SANS & rTMS & Sham coil & 10 & $110 \%$ & 15 & 30000 & L-DLPFC \\
\hline Prikryl & 2014 & $\begin{array}{l}\text { Czech } \\
\text { Republic }\end{array}$ & 18 & 17 & 33.2 & $\mathrm{~N}$ & PP & Par & $100 \%$ & $13 \%$ & PANSS-N & rTMS & Sham coil & 10 & $110 \%$ & 15 & 42000 & L-DLPFC \\
\hline Quan & 2015 & China & 78 & 39 & 46.6 & $\mathrm{Y}$ & ITT & Par & $62 \%$ & $0 \%$ & $\begin{array}{l}\text { PANSS-N, } \\
\text { SANS }\end{array}$ & rTMS & $90^{\circ}$ & 10 & $80 \%$ & 20 & 16000 & L-DLPFC \\
\hline Rabany & 2014 & Israel & 15 & 8 & 34.8 & $\mathrm{Y}$ & ITT & Par & $70 \%$ & $17 \%$ & $\begin{array}{l}\text { PANSS-N, } \\
\text { SANS }\end{array}$ & $\begin{array}{l}\text { deep- } \\
\text { TMS }\end{array}$ & $\mathrm{NI}$ & 20 & $120 \%$ & 20 & 19200 & L-DLPFC \\
\hline Ren & 2011 & China & 12 & 11 & 34.2 & $\mathrm{NI}$ & $\mathrm{NI}$ & $\mathrm{NI}$ & $\mathrm{NI}$ & $\mathrm{NI}$ & PANSS-N & rTMS & $\mathrm{NI}$ & 20 & $80 \%$ & 10 & 8000 & B-DLPFC \\
\hline Rosa & 2007 & Brazil & 6 & 5 & 31.9 & $\mathrm{~N}$ & $\mathrm{NI}$ & Par & $55 \%$ & $0 \%$ & PANSS-N & rTMS & Sham coil & 1 & $90 \%$ & 10 & 9600 & L-TPC \\
\hline Rosenberg & 2012 & Israel & 5 & 5 & 39.2 & $\mathrm{~N}$ & PP & Par & $78 \%$ & $44 \%$ & SANS & $\begin{array}{l}\text { deep- } \\
\text { TMS }\end{array}$ & Sham coil & 1 & $110 \%$ & 10 & 6000 & L-TPC \\
\hline Saba & 2006 & France & 8 & 8 & 30.6 & $\mathrm{~N}$ & PP & Par & $81 \%$ & $11 \%$ & PANSS-N & rTMS & Sham coil & 1 & $80 \%$ & 14 & 4200 & L-TPC \\
\hline Schneider & 2008 & USA & 33 & 15 & 41.1 & $Y$ & PP & Par & $33 \%$ & $6 \%$ & SANS & rTMS & Sham coil & $\begin{array}{l}1- \\
10\end{array}$ & $110 \%$ & 20 & Var & L-DLPFC \\
\hline Singh & 2020 & India & 15 & 15 & 31.0 & $\mathrm{Y}$ & ITT & Par & $57 \%$ & $13 \%$ & $\begin{array}{l}\text { PANSS-N, } \\
\text { SANS }\end{array}$ & rTMS & Sham coil & 20 & $100 \%$ & 20 & 40000 & L-DLPFC \\
\hline Tikka & 2017 & India & 8 & 7 & 26.5 & $\mathrm{~N}$ & PP & Par & $\mathrm{NI}$ & $25 \%$ & PANSS-N & cTBS & Sham coil & 50 & $80 \%$ & 10 & 9000 & R-IPL \\
\hline Wang & 2020 & China & 25 & 25 & $\mathrm{NI}$ & $\mathrm{N}$ & $\mathrm{NI}$ & Par & $\mathrm{NI}$ & $\mathrm{NI}$ & $\begin{array}{l}\text { PANSS-N, } \\
\text { SANS }\end{array}$ & iTBS & $\mathrm{NI}$ & $\mathrm{NI}$ & $\mathrm{NI}$ & 14 & $\mathrm{NI}$ & L-DLPFC \\
\hline Wen-Xiang & 2012 & China & 76 & 31 & 42,7 & $\mathrm{~N}$ & ITT & Par & $71 \%$ & $12 \%$ & PANSS-N & rTMS & Sham coil & 1 & $80 \%$ & 20 & 16000 & L-DLPFC \\
\hline Wobrock & 2015 & Germany & 76 & 81 & 35.3 & $Y$ & ITT & Par & $75 \%$ & $10 \%$ & PANSS-N & rTMS & $45^{\circ}$ & 10 & $110 \%$ & 15 & 15000 & L-DLPFC \\
\hline Xiu & 2020 & China & 67 & 30 & 52.4 & $Y$ & ITT & Par & $100 \%$ & $19 \%$ & PANSS-N & rTMS & Sham coil & $\begin{array}{l}10- \\
20\end{array}$ & $110 \%$ & 40 & Var & L-DLPFC \\
\hline Xu & 2006 & China & 33 & 34 & 38.0 & $\mathrm{NI}$ & $\mathrm{NI}$ & $\mathrm{NI}$ & $\mathrm{NI}$ & $\mathrm{NI}$ & PANSS-N & rTMS & $\mathrm{NI}$ & $\mathrm{NI}$ & $80 \%$ & 10 & Var & $\begin{array}{l}\text { L-DLPFC, } \\
\text { B-PC }\end{array}$ \\
\hline Xu & 2015 & China & 60 & 30 & 45.3 & $\mathrm{NI}$ & $\mathrm{NI}$ & $\mathrm{NI}$ & $\mathrm{NI}$ & $\mathrm{NI}$ & PANSS-N & rTMS & $\mathrm{NI}$ & $\begin{array}{l}5- \\
10\end{array}$ & $80 \%$ & 10 & 25000 & L-DLPFC \\
\hline Zhang & 2010 & China & 15 & 15 & 38 & $\mathrm{NI}$ & $\mathrm{NI}$ & $\mathrm{NI}$ & $\mathrm{NI}$ & $\mathrm{NI}$ & PANSS-N & TBS & $\mathrm{NI}$ & $\mathrm{NI}$ & $80 \%$ & 20 & 48000 & L-DLPFC \\
\hline Zhang & 2015 & China & 35 & 34 & 39.9 & $\mathrm{NI}$ & $\mathrm{NI}$ & $\mathrm{NI}$ & $\mathrm{NI}$ & $\mathrm{NI}$ & PANSS-N & rTMS & $\mathrm{NI}$ & 10 & $\mathrm{NI}$ & 20 & 16000 & L-DLPFC \\
\hline Zhao & 2014 & China & 71 & 22 & 47.9 & $\mathrm{Y}$ & PP & Par & $56 \%$ & $3 \%$ & $\begin{array}{l}\text { PANSS-N, } \\
\text { SANS }\end{array}$ & $\begin{array}{l}\text { rTMS, } \\
\text { iTBS }\end{array}$ & $180^{\circ}$ & $\begin{array}{l}10- \\
50\end{array}$ & Var & 20 & Var & L-DLPFC \\
\hline Zheng & 2012 & China & 56 & 17 & 56.3 & $\mathrm{NI}$ & $\mathrm{NI}$ & Par & $\mathrm{NI}$ & $\mathrm{NI}$ & PANSS-N & $\begin{array}{l}\text { rTMS, } \\
\text { TBS }\end{array}$ & $\mathrm{NI}$ & $\begin{array}{l}10- \\
20\end{array}$ & $80 \%$ & 5 & $\begin{array}{l}2000- \\
6000\end{array}$ & L-DLPFC \\
\hline Zhuo & 2019 & China & 33 & 27 & 30.0 & $\mathrm{Y}$ & PP & Par & $37 \%$ & $14 \%$ & PANSS-N, & rTMS & $180^{\circ}$ & 20 & $90 \%$ & 20 & 40000 & L-DLPFC \\
\hline
\end{tabular}


$N_{a}:$ Number of participants active group, $N_{c}$ : Number of participants control group, PNS: Patients with predominant negative symptoms, N: No, Y: Yes, ITT: Intentionto-treat, PP: Per protocol, NI: No information, Par: Parallel, PANSS-N: Positive and Negative Syndrome Scale - Negative subscale, SANS: Scale for the Assessment of Negative Symptoms, BPRS-N/D: Brief Psychiatric Rating Scale - Negative/Disorganization factor. TMS: Transcranial Magnetic Stimulation, Hz: Herz (frequency of stimulation), \% MT: Percent of Motor Threshold, rTMS: repetitive Transcranial Magnetic Stimulation, TBS: theta burst stimulation, cTBS: continuous theta burst stimulation, iTBS: Intermittent theta burst stimulation, B-DLPFC: Bilateral dorsolateral prefrontal cortex, L-DLPFC: Left dorsolateral prefrontal cortex, R-DLPFC: Right dorsolateral prefrontal cortex, MC: Medullar cerebellum, L-TPC: Left tempero-parietal cortex, L-STS: Left superior temporal sulcus, B-PFC: Bilateral prefrontal cortex, L-PFC: Left prefrontal cortex, R-PFC: Right prefrontal cortex, B-PC: Bilateral parietal cortex, L-STG: Left superior temporal gyrus, L-MTG: Left medial temporal gyrus, R-IPL: Right inferior parietal lobule. NI: No information. ${ }^{\circ}$ in the sham type column indicates if the coil was rotated as sham method and by how many degrees. 
medRxiv preprint doi: https://doi.org/10.1101/2021.11.05.21265787; this version posted November 8, 2021. The copyright holder for this preprint (which was not certified by peer review) is the author/funder, who has granted medRxiv a license to display the preprint in perpetuity.

All rights reserved. No reuse allowed without permission.

Figure 2: Forest plot of standardized mean differences (effect size)

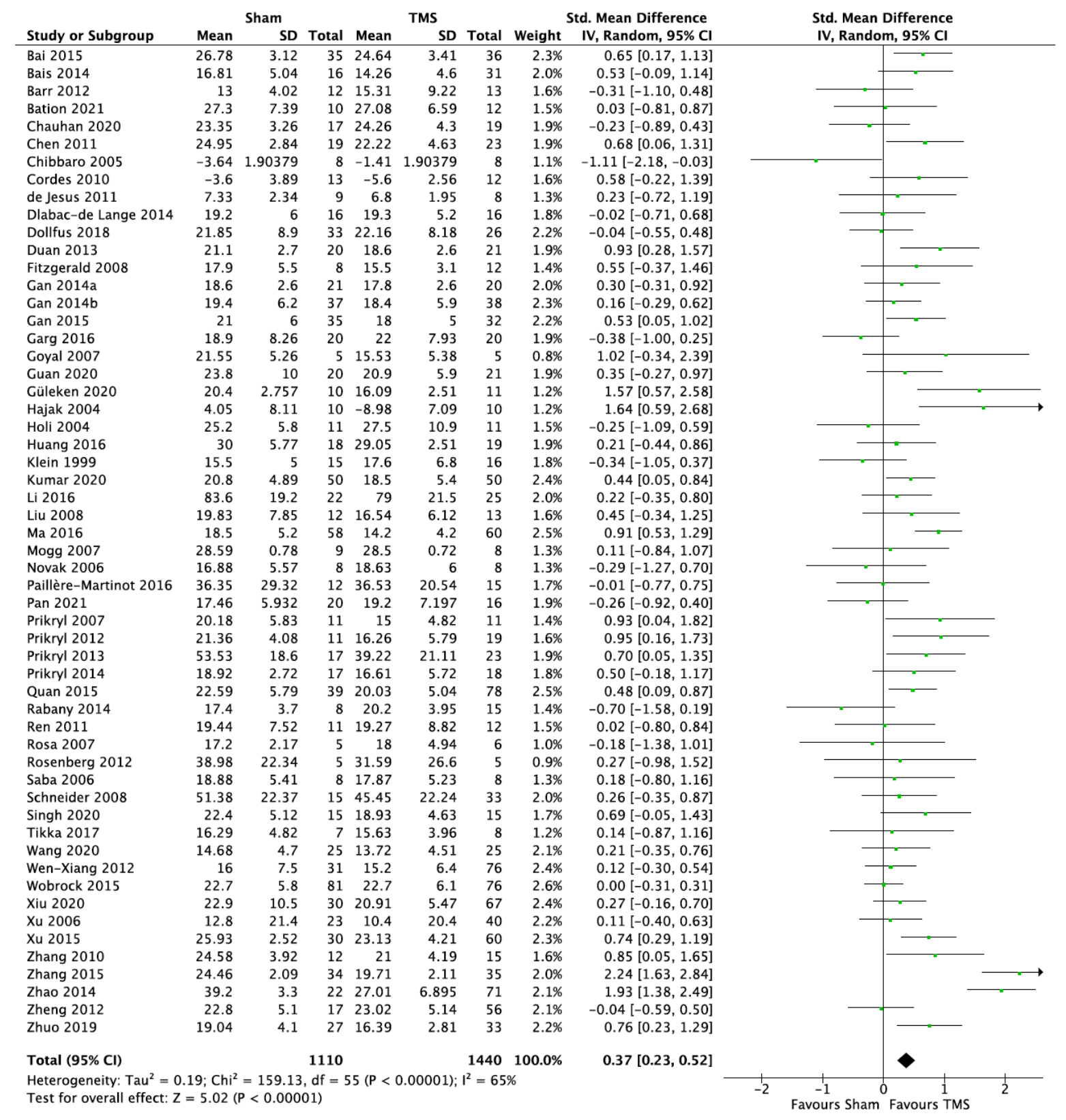


medRxiv preprint doi: https://doi.org/10.1101/2021.11.05.21265787; this version posted November 8, 2021. The copyright holder for this preprint (which was not certified by peer review) is the author/funder, who has granted medRxiv a license to display the preprint in perpetuity.

All rights reserved. No reuse allowed without permission.

Table 2: Results of overall effect size and subgroup analyses

\begin{tabular}{|c|c|c|c|c|c|}
\hline & & $N$ & $\begin{array}{l}\text { SMD ( } 95 \% \text { confidence } \\
\text { interval) }\end{array}$ & $p$ & $I^{2}$ \\
\hline \multicolumn{2}{|c|}{ Overall standardized mean difference (SMD) } & 2550 & $0.37(0.23,0.52)$ & $<0.00001$ & $65 \%$ \\
\hline \multirow{2}{*}{ Site } & L-DLPFC & 2072 & $0.51(0.33,0.69)$ & $<0.00001$ & $71 \%$ \\
\hline & Other* & 490 & $0.05(-0.14,0.23)$ & 0.62 & $24 \%$ \\
\hline \multirow{2}{*}{$\begin{array}{l}\text { Stimulation } \\
\text { Frequency } \\
\text { (rTMS only) }\end{array}$} & $1 \mathrm{~Hz}^{*}$ & 304 & $0.05(-0.18,0.29)$ & 0.66 & $5 \%$ \\
\hline & $>1 \mathrm{~Hz}$ & 1853 & $0.52(0.42,0.62)$ & $<0.00001$ & $78 \%$ \\
\hline \multirow{2}{*}{$\begin{array}{l}\text { Stimulation } \\
\text { intensity }\end{array}$} & $<100 \%$ of $\mathrm{MT}$ & 1026 & $0.26(0.06,0.46)$ & 0.01 & $53 \%$ \\
\hline & $\geq 100 \%$ of $\mathrm{MT}$ & 1427 & $0.42(0.23,0.61)$ & $<0.0001$ & $63 \%$ \\
\hline \multirow{2}{*}{$\mathrm{Age}^{\star \star}$} & $\leq$ median $^{*}$ & 1026 & $0.33(020,0.45)$ & $<0.00001$ & $46 \%$ \\
\hline & $>$ median & 1352 & $0.40(0.14,0.66)$ & 0.002 & $78 \%$ \\
\hline \multirow{3}{*}{ Type } & rTMS & 2218 & $0.47(0.28,0.66)$ & $<0.00001$ & $76 \%$ \\
\hline & TBS & 352 & $0.48(-0.01,0.96)$ & 0.06 & $78 \%$ \\
\hline & Deep-TMS* & 33 & $-0.34(-1.07,0.38)$ & 0.36 & $47 \%$ \\
\hline $\begin{array}{l}\text { Excluding } \\
\text { data from } \\
\text { graphs }\end{array}$ & & 2365 & $0.40(0.24,0.56)$ & $<0.00001$ & $69 \%$ \\
\hline $\begin{array}{l}\text { Excluding } \\
\text { high risk of } \\
\text { Bias } \\
\text { studies }^{\star * *}\end{array}$ & & 813 & $0.35(0.08,0.62)$ & 0.01 & $69 \%$ \\
\hline $\begin{array}{l}\text { Excluding } \\
\text { change- } \\
\text { from- } \\
\text { baseline } \\
\text { studies }\end{array}$ & & 2548 & $0.38(0.24,0.53)$ & $<0.00001$ & $66 \%$ \\
\hline $\begin{array}{l}\text { Participants } \\
\text { with PNS }\end{array}$ & & 1034 & $0.45(0.20,0.70)$ & 0.0005 & $69 \%$ \\
\hline $\begin{array}{l}\text { Follow up } \\
\text { ( } \geq 4 \text { weeks } \\
\text { after end of } \\
\text { treatment }^{*}\end{array}$ & & 695 & $0.25(0.09,0.40)$ & 0.002 & $42 \%$ \\
\hline $\begin{array}{l}\text { Depressive } \\
\text { symptoms* }\end{array}$ & & 743 & $0.03(-0.12,0.18)$ & 0.72 & $30 \%$ \\
\hline $\begin{array}{l}\text { Excluding } \\
\text { data taken } \\
\text { from earlier } \\
\text { reviews }\end{array}$ & & 1784 & $0.29(0.12,0.45)$ & 0.0006 & $60 \%$ \\
\hline
\end{tabular}

L-DLPFC: Left dorsolateral prefrontal cortex, rTMS: repetitive transcranial magnetic stimulation, MT: motor threshold, TBS: Theta burst stimulation, deep-TMS: deep transcranial magnetic stimulation, PNS: Predominant negative symptoms. *calculated using fixed effect analysis due to heterogeneity $<50 \%,{ }^{* *}$ median $=35,5$ years, $* * *$ Non-English language articles also excluded as they were not evaluated. Some studies had several active treatment groups and are included in several analyses. 
Figure 3: Funnel plot

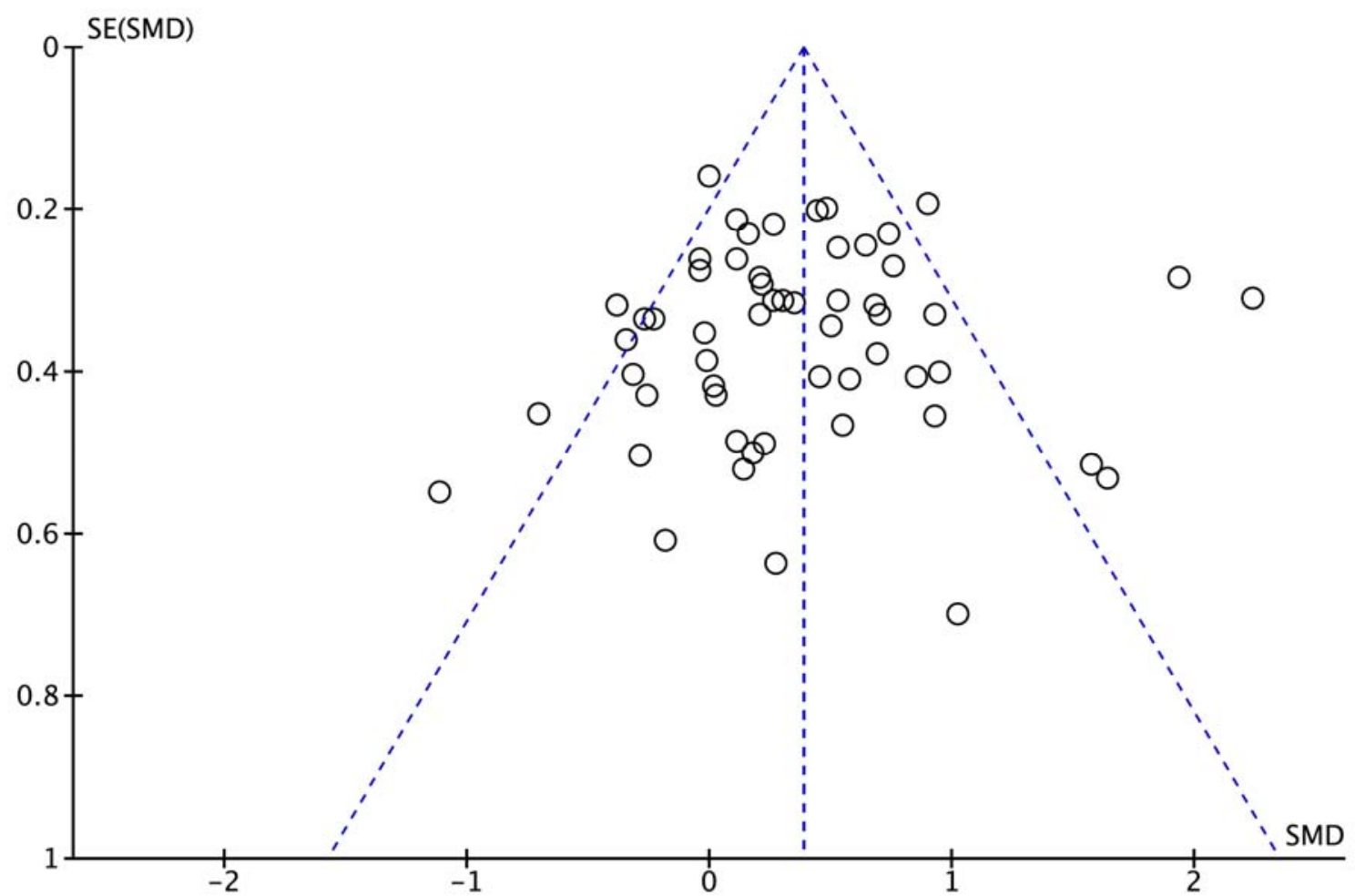

SE: Standard error, SMD: Standardized mean difference 